\title{
Application of the shrinking core model for dissolution of serpentinite in an acid solution
}

\author{
Agnieszka Didyk-Mucha ${ }^{1}$, Agnieszka Pawlowska ${ }^{1}$, and Zygmunt Sadowski ${ }^{1, a}$ \\ ${ }^{1}$ Department of Chemical Engineering, Wroclaw University of Technology, Wybrzeze Wyspianskiego 27, \\ 50-370 Wroclaw, Poland
}

\begin{abstract}
Serpentinites have the potential to be used as carbo dioxide capture and storage materials. Acid dissolution is the first stage of this process. This study examined how a shrinking core model can be applied to the dissolution of serpentinite in sulphuric acid. The dissolution process was assumed to occur in two stages: an initial step involving the surface dissolution of serpentinite pieces, and a second step involving surface chemical reaction, described by the shrinking core model. The model formulation was completed by relating the dissolution rate of serpentinite to the surface changes.
\end{abstract}

\section{Introduction}

Mineral carbon dioxide sequestration is a promising method for reducing carbon dioxide emission. Mineral carbonation transform carbon dioxide into the form of geologically and thermodynamically stable magnesium carbonate. This process can be considered as a result of two steps: (1) dissolution of silicate minerals and (2) the reaction between either calcium or magnesium cations and $\mathrm{CO}_{2}$ to create carbonates [1-6]. For aqueous carbonation, magnesium silicate minerals such as serpentinite and olivine are frequently used [7-9]. This process can be described by the following reactions

$$
\begin{gathered}
\mathrm{Mg}_{3} \mathrm{Si}_{2} \mathrm{O}_{5}(\mathrm{OH})_{4}+3 \mathrm{CO}_{2}=3 \mathrm{MgCO}_{3}+2 \mathrm{SiO}_{2}+\mathrm{H}_{2} \mathrm{O} \\
\mathrm{Mg}_{2} \mathrm{SiO}_{4}+2 \mathrm{CO}_{2}=2 \mathrm{MgCO}_{3}+\mathrm{SiO}_{2} .
\end{gathered}
$$

It is evident that carbonation of silicate minerals involves two sub-processes: dissolution of silicate minerals and carbonate precipitation. In the aqueous carbonation process, dissolution of serpentinite was considered to be the rate-limiting step [10]. In a previous study, serpentinite was dissolved in $\mathrm{HCl}$ and $\mathrm{HNO}_{3}$ acid solutions and hydromagnesite precipitation was obtained at $\mathrm{pH}$ level of 9 with addition of $\mathrm{NaOH}$ [11]. Generally, the carbonation process with the leached solution was promoted using a basic medium. Carbonation of a Mg-leaching solution was performed at $\mathrm{pH} 9.5$ [12].

A significant problem has been previously observed with the diffusion-limiting $\mathrm{SiO}_{2}$ layer in silicate minerals. Some effect had been undertaken to eliminate this problem by selective flotation of quartz [13]. However, selective separation of free quartz particles has not eliminated this problem. A shrinking core model has been considered for leaching of zinc ores containing silicates with

${ }^{a}$ Corresponding author: zygmunt.sadowski@pwr.edu.pl 
sulphuric acid [14]. The presence of porous layer must be considered during the dissolution of serpentinite particles.

According to the shrinking particle model of the dissolution, the reaction is considered to take place first on the outer surface of serpentinite ore particles. The porous zone penetrates into the solid particles and the particles shrink during the leaching process. The kinetics of the leaching process involves three sub-processes that occur during leaching:

i. the external diffusion of acid to the solid surface,

ii. internal diffusion in the porous layer from the solution to the core surface and vice versa,

iii. leaching reaction on the core surface.

The rate of leaching (dissolution) is generally controlled diffusion through the porous layer or the dissolution reaction at the mineral surface of un-reacted particles [15].

One major factor that can affect interpretation of leaching data is the particle size distribution of a solid material. It was observed that the initial rate of leaching increased due to increase in the small particle fraction. In a previous study, the rate of leaching was observed to decrease during the latter part of the process due to the decrease in the large particle fraction [16]. The leaching process can also be described based on the residual volume of particles:

$$
X(t)=1-\left[\frac{r(t)}{r_{0}}\right]^{3}
$$

Furthermore, the rate of leaching was related to the surface area of solid particles [17]. The experimental results presented in a previous paper [18] indicated that the rate at with leaching was a function of surface area. The primary hypothesis made in this study was that the increase in the surface area of leached ore particles was directly proportional to decrease in the magnesium content of the ore particles during the initial dissolution period. In this study, we investigated dissolution of serpentinite rock particles from the Grochow mine. This serpentinite ore was the most interesting for carbon dioxide capture (CCS). The main aim of this study was to correlate the surface area of mineral particle to the corresponding dissolution kinetic.

\section{Materials and methods}

Mineral samples of serpentinite ore were delivered from Grochowa mine (Magnezyty "Grochow" S.A.), located in Lower Silesia (Poland). The ore material was dry-ground using a porcelain ball mill and wet sieved. Two size fractions were separated. A size fraction of $+45-71 \mu \mathrm{m}$ was used for the dissolution experiments. The mineral samples were analysed by an X-ray diffraction method (Fig. 1). The XRD pattern shows that the mineral samples consisted of $70 \mathrm{wt} \%$ serpentinite minerals (antigorite, lizardite) $10 \mathrm{wt} \%$ talc, $5 \mathrm{wt} \%$ clinochlore, $8 \mathrm{wt} \%$ actinolite, $3 \mathrm{wt} \%$ quartz, and $2 \mathrm{wt} \%$ magnesite. The results of the chemical analysis of mineral sample are presented in Table 1.

Table 1. The elemental analysis of serpentinite rock (XRF).

\begin{tabular}{|c|c|}
\hline $\begin{array}{l}\text { Element and } \\
\text { compound }\end{array}$ & $\begin{array}{l}\text { Results of } \\
\text { analysis [\%] }\end{array}$ \\
\hline $\mathrm{SiO}_{2}$ & 40.48 \\
\hline $\mathrm{TiO}_{2}$ & 0.02 \\
\hline $\mathrm{Al}_{2} \mathrm{O}_{3}$ & 1.15 \\
\hline $\mathrm{Fe}_{2} \mathrm{O}_{3}$ & 8.49 \\
\hline $\mathrm{MgO}$ & 35.35 \\
\hline $\mathrm{CaO}$ & 1.3 \\
\hline $\mathrm{Na}_{2} \mathrm{O}$ & 0.17 \\
\hline $\mathrm{K}_{2} \mathrm{O}$ & 0.02 \\
\hline
\end{tabular}




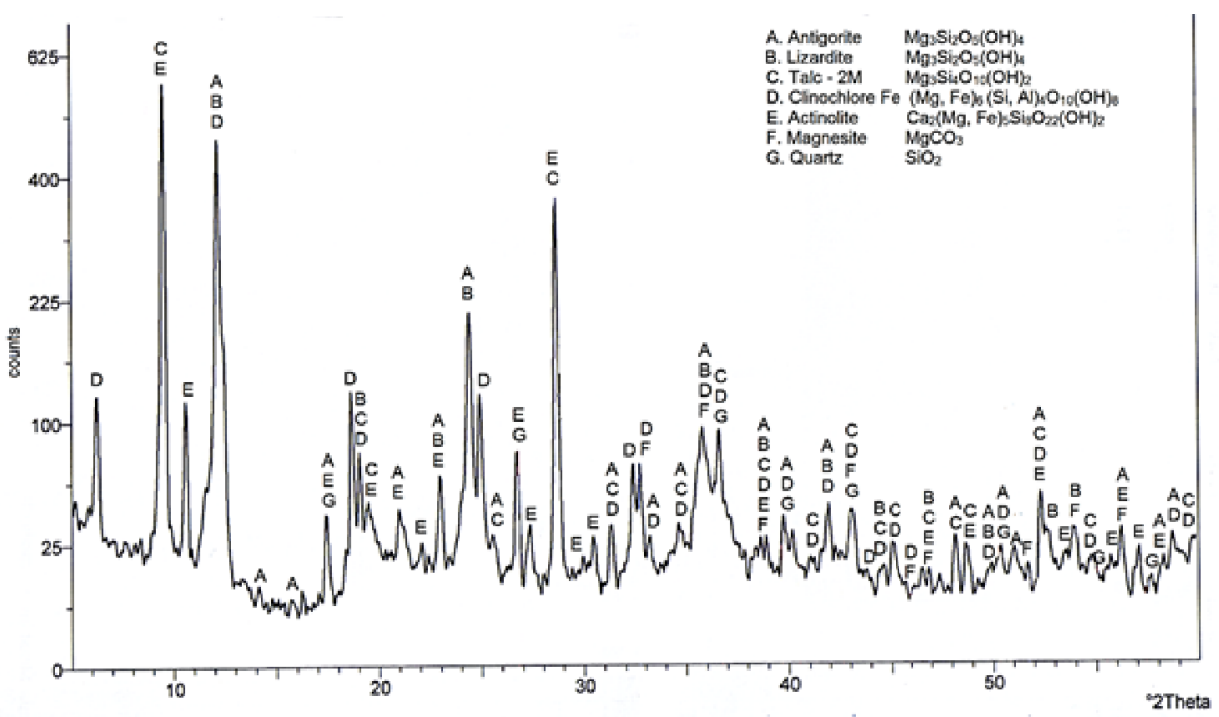

Figure 1. X-Ray diffractogram of serpentinite sample.

The particle size distributions of the mineral samples (Fig. 2) were determined using the Mastersizer 2000 (Malvern) particle analyser. The specific surface area of the mineral sample was measured using a FlowSorb II 2300 instrument. The BET method was employed to determine the surface area of investigated mineral fraction which was equal to $16.38 \mathrm{~g} \mathrm{~m}^{-2}$.

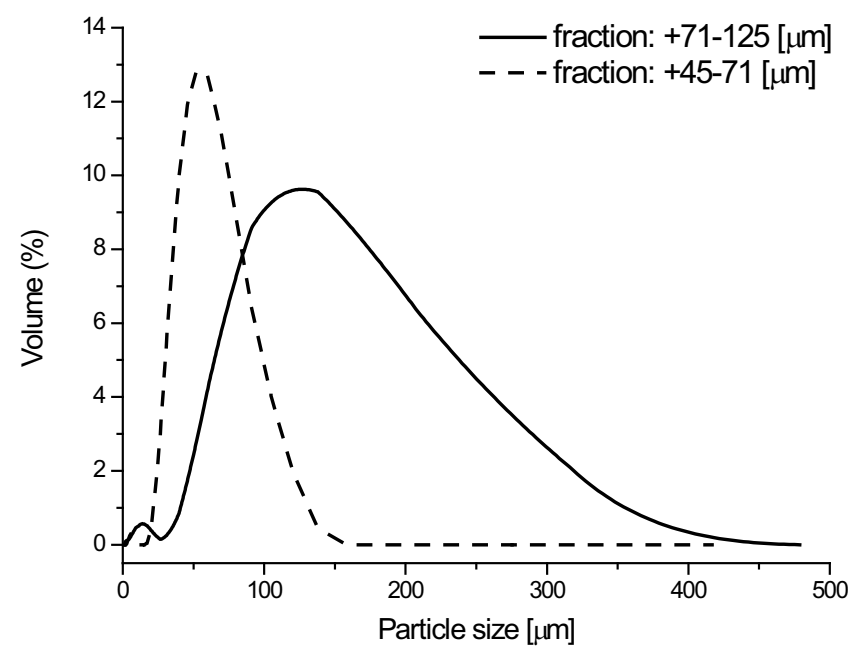

Figure 2. Particle size distributions of mineral samples ( $+45-71$ and $+71-125 \mu \mathrm{m}$ fractions).

Dissolution experiments were carried out in closed Erlenmeyer flasks $(200 \mathrm{ml})$ at room temperature $\left(20^{\circ} \mathrm{C}\right)$. Two grams of each mineral sample was dissolved in $100 \mathrm{ml}$ of sulphuric acid solution. The concentrations of the acid solution were 1.0, 2.0, and $2.5 \mathrm{M}$, respectively. The concentrations of magnesium and calcium ions in the solution were periodically measured. The extent of magnesium and calcium leaching recovery $(\mathrm{X})$ was calculated using formula 


$$
X_{M g / C a}=\frac{C_{M g / C a} V}{m Y_{M g / C a}} 100[\%]
$$

where: $c_{\mathrm{Mg} / \mathrm{Ca}}$ the concentration of $\mathrm{Mg}^{2+}$ or $\mathrm{Ca}^{2+}$ ions in the solution $\left[\mathrm{g} / \mathrm{dm}^{3}\right], v$ the solution volume $\left[\mathrm{dm}^{3}\right], \mathrm{m}$ the weight of sample $[\mathrm{g}], Y_{\mathrm{Mg} / \mathrm{Ca}}$ the content of $\mathrm{Mg}$ or $\mathrm{Ca}$ in the sample.

\section{Results and discussion}

Serpentine is the main component of serpentinite rock. Serpentine is a silicate mineral with tetrahedral silica-type and octahedral brucite-type layers [10]. The chemistry of serpentinite ore acid leaching process is well understood [11,12]. Partial decomposition of the silicate structure of serpentine minerals occurs during acid dissolution. Such behaviour is known as incongruent dissolution [7]. Dissolution of serpentinite using sulphuric acid could form the basis of a commercial technology used for carbonation of silicate minerals. In this work we tested dissolution of serpentinite using three sulphuric acid concentrations $(1.0,2.0$, and $2.5 \mathrm{M})$. The kinetics of mineral dissolution were monitored in terms of concentration of calcium and magnesium ions in each solution. Figure 3 shows the changes in the concentration of calcium ions that were extracted.

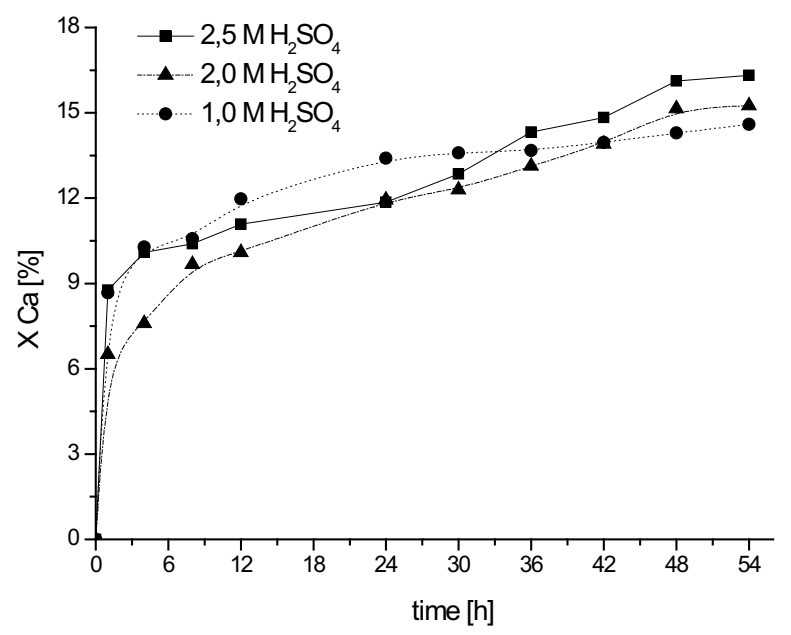

Figure 3. Kinetics of calcium extraction from serpentinite ore sample $(+45-71 \mu \mathrm{m})$ at room temperature.

Data regarding magnesium extraction are presented in Fig. 4. The concentration of calcium and magnesium extracted indicate that the rate-limiting step of dissolution of serpentinite in $\mathrm{H}_{2} \mathrm{SO}_{4}$ is most likely due to formation of a passive silica layer.

Dissolution of serpentinite increases with increasing acid concentration. In a previous study, this concentration dependence was observed for dissolution of serpentinite ore in a trisodium citrate solution.

The effect of acid concentration on the particle diameter $\left(d_{50}\right)$ of serpentinite ore particles $(+45$ $71 \mu \mathrm{m}$ fraction) is illustrated in Fig. 5. As the serpentinite dissolution process proceeds, the particle radius decreases. The dissolution rate $D$ is defined as the rate of change in the characteristic diameter $d_{50}$ of the particle population.

$$
\frac{d d_{50}}{d t}=-D\left(d_{50}\right)
$$

The dissolution rate is also related to the particle surface area. The available surface area of serpentinite mineral particles was observed to vary throughout the dissolution process, as shown in 
Fig. 6. The total surface area of the mineral particles $(+45-71 \mu \mathrm{m}$ fraction) increased significantly during the second stage of the leaching process.

The surface area $(S)$ represents the availability of dissolution reaction sites, and it is assumed that the concentration of ions varies directly with the surface area. The rate of dissolution can be expressed as follows.

$$
\frac{d c}{d t}=k S
$$

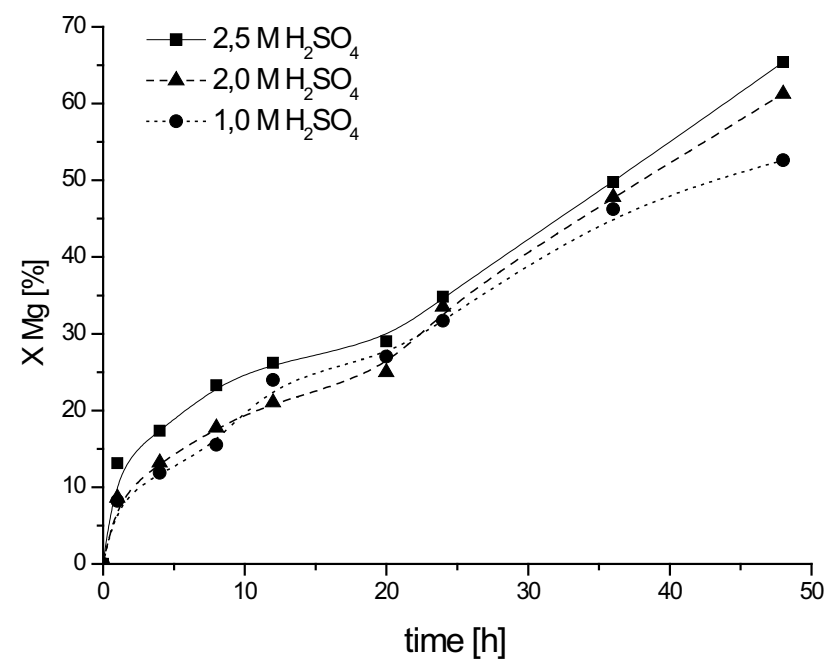

Figure 4. Kinetics of magnesium extraction from serpentinite ore sample $(+45-71 \mu \mathrm{m})$ at room temperature.

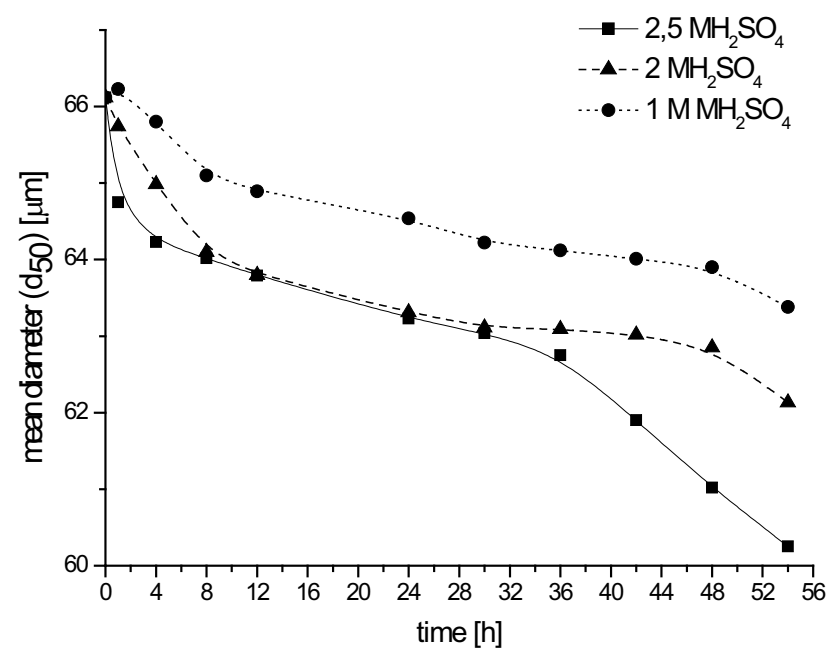

Figure 5. Mean diameter changes of serpentinite particles $(+45-71 \mu \mathrm{m})$ during an acid dissolution. 


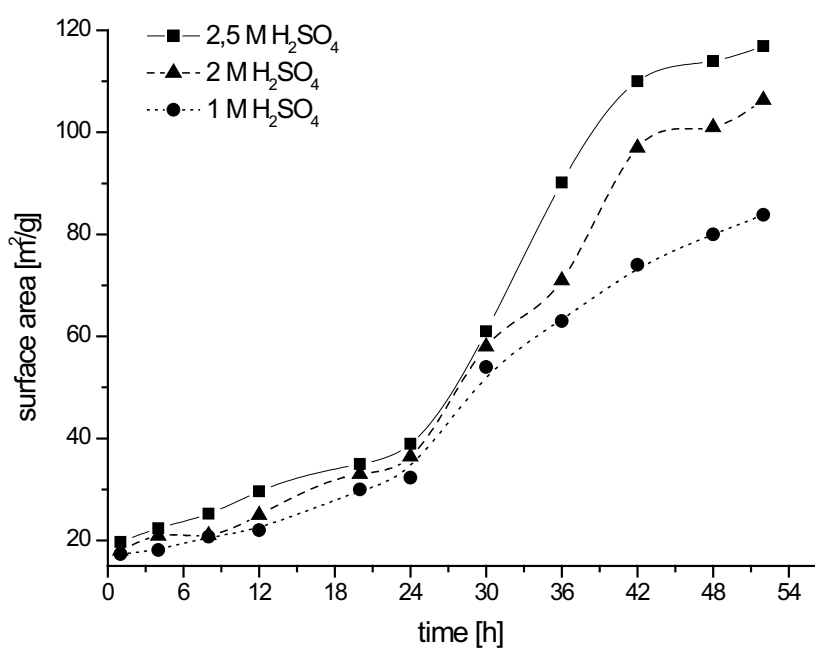

Figure 6. Surface area changes of serpentinite ore particles $(+45-71 \mu \mathrm{m})$ during acid dissolution.

According to [25], the particle surface area changed during mineral dissolution. The BET surface area of sandstones was observed to increase during dissolution [26]. Figure 6 indicates that after $24 \mathrm{~h}$ of dissolution the surface area of the serpentinite particles $(+45-71 \mu \mathrm{m}$ fraction) dramatically increased. This increase in the surface area corresponded to decrease in the particle radius (Fig. 5). Serpentine, $\mathrm{Mg}_{3} \mathrm{Si}_{2} \mathrm{O}_{5}(\mathrm{OH})_{4}$, is a sheet silicate mineral that consists of layers of $\mathrm{SiO}_{4}$ tetrahedra and $\mathrm{Mg}(\mathrm{OH})_{2}$ octahedral. The silica-rich layer remains passive during dissolution. The observed increase in surface area can be correlated to formation of the silica porous layer during acid leaching.

To determine the mechanism of serpentine rock dissolution in sulphuric acid, the dissolution process was analysed according to shrinking particle and shrinking core models [27]. In this study, the kinetic analysis was performed based on experimental data regarding surface area changes, which indicate that the dissolution process may be explained by the formation of a porous layer. As shown in Fig. 7, dissolution of serpentinite particles can be divided into two stages. The ordinary shrinking core model does not apply in the initial stage. Modification of shrinking core model should be as follows.

The primary assumption made in constructing the model is that the increase in the surface area is directly proportional to the decrease in the metal $(\mathrm{Ca}, \mathrm{Mg})$ content in the solid particle at the surface:

$$
\frac{d S}{d t}=k c_{C a, M g} S \text {. }
$$

To simplify our calculation we introduced constant $B$ as a substitute of $k c_{C a, M g}$. Thus, the new equation has the form

$$
\frac{d S}{d t}=B S
$$

The solution of Equation (6) for the initial condition $S_{(\mathrm{t}=0)}=S_{0}$ can be written as:

$$
S(t)=S_{0} e^{B t},
$$

and in the logarithmic form as:

$$
\ln (S)=B t+\ln \left(S_{0}\right) .
$$


Logarithmic equation 10 properly describes the first stage of the serpentinite dissolution process (Fig. 8).

Now, we consider the second stage of dissolution. If one assumes that serpentinite particles are spherical and the chemical reaction is the rate-controlling step, then the shrinking particle model can be used. The kinetics of this process is described by the following equation:

$$
1(1-\alpha)^{\frac{1}{3}}=K_{a p p} t
$$

where $K_{\text {app }}=\frac{k[\text { acid }]^{n}}{3 \rho_{\text {solid }} R_{0}}$ and $R_{0}$ is the particle radius.

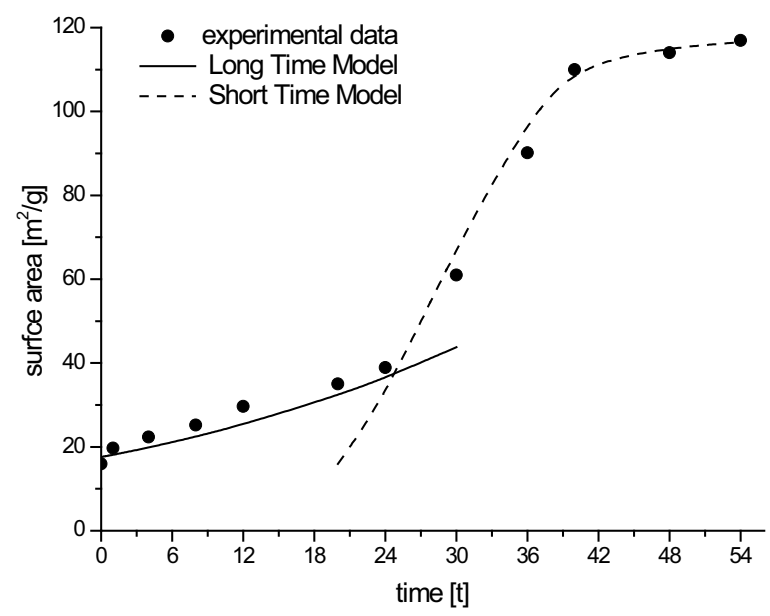

Figure 7. The "short time" and "long time" model data compared with the experimental data for $+45-71 \mu \mathrm{m}$ fraction $\left(2.5 \mathrm{M} \mathrm{H}_{2} \mathrm{SO}_{4}\right)$.

Formation of a porous (ash/inert) layer affects the surface area of serpentinite particles during dissolution. To describe the increase in the surface area during ash layer creation, we introduce the modified module $d\left(S_{\mathrm{k}}-S\right)$. Thus, the surface changes can be described by a new Equation:

$$
\frac{d S}{d t}=B S d\left(S_{k}-S\right)
$$

For the initial conditions $S_{(\mathrm{t}=0)}=S_{0}$, the solution of Equation (12) is

$$
S(t)=\frac{S_{0} e^{B t}}{1-\frac{S}{S_{k}}\left(1-e^{B t}\right)} .
$$

The above equation can be transformed into the following logistic equation:

$$
\ln \left(\frac{S}{S_{k}-S}\right)=S_{k} B t+\ln \left(\frac{S}{s_{k}-S_{0}}\right)=S_{k} B t+D,
$$

where: $D=\ln \left(\frac{S}{S_{k}-S}\right)=-2.0873$.

This logistic equation is a linear function that accurately describes only the final stage of the serpentinite ore dissolution process (Fig. 9). 


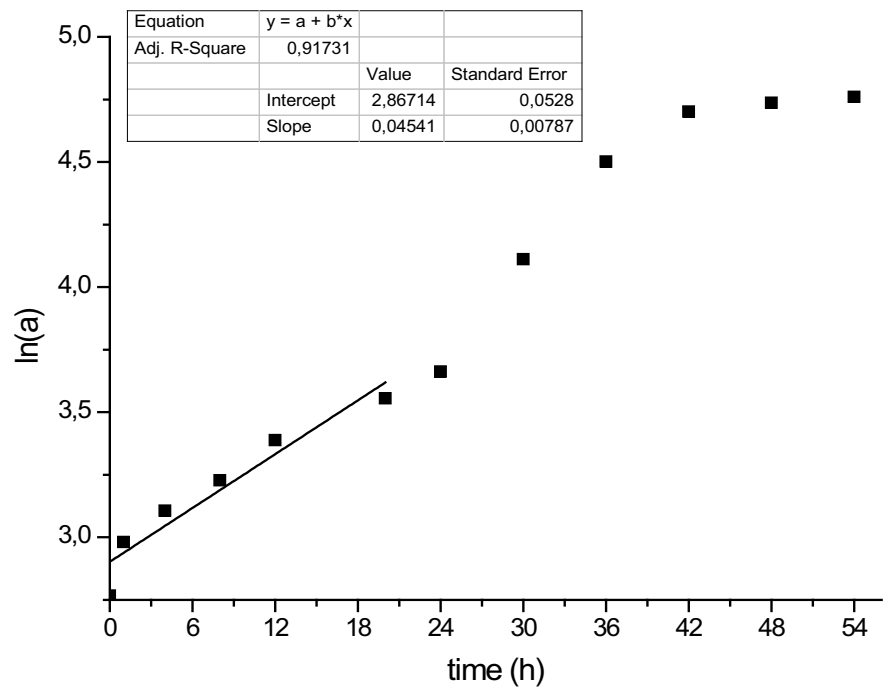

Figure 8. Linear dependence of surface changes at the initial period of leaching process.

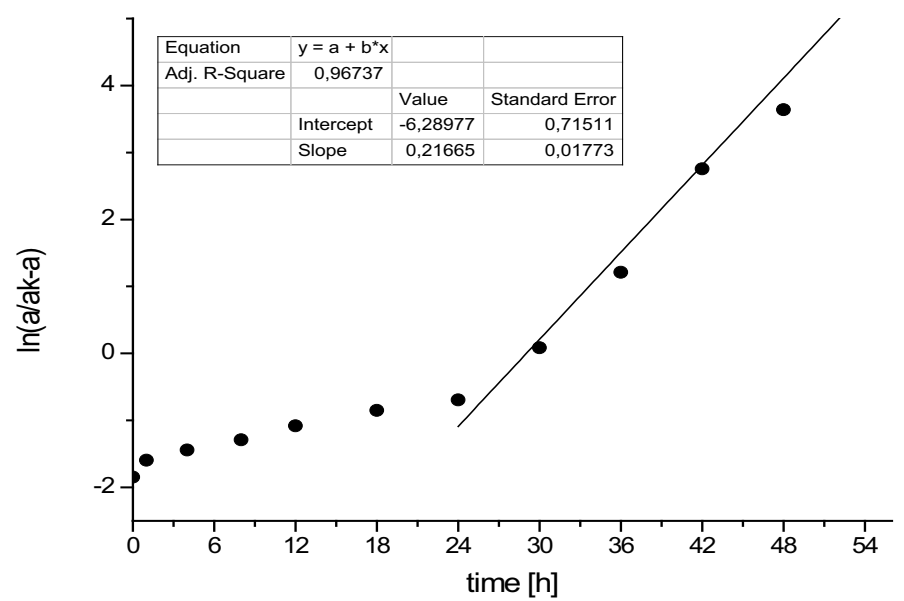

Figure 9. Linear dependence of surface changes at the final stage of leaching process.

The porous structure of surface layer after 56 hours of leaching is presented in Fig. 10 (SEM picture), while Fig. 11. presents the picture of surface before leaching. 


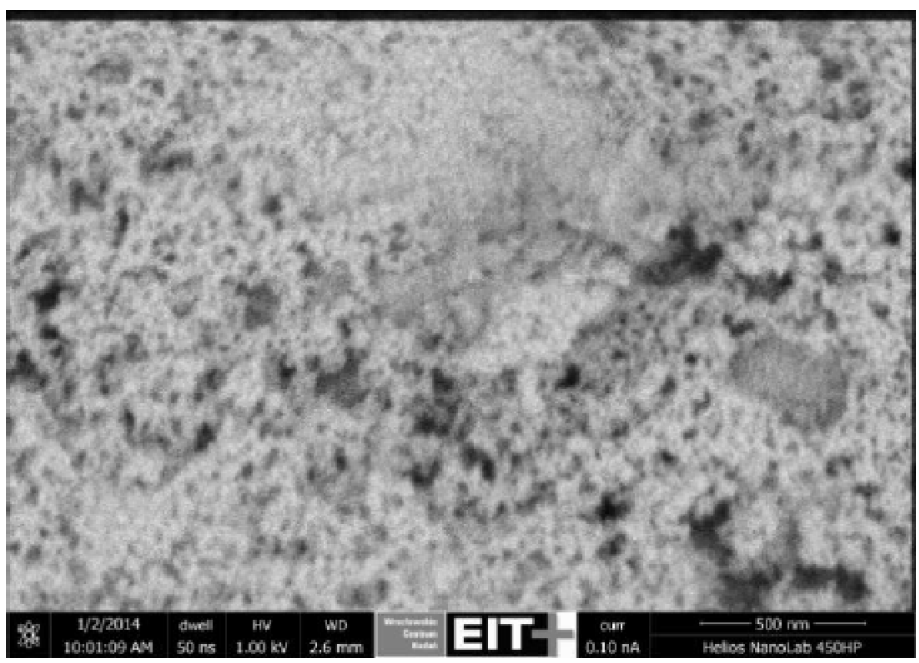

Figure 10. Surface of serpentine ore after 56 hours of leaching.

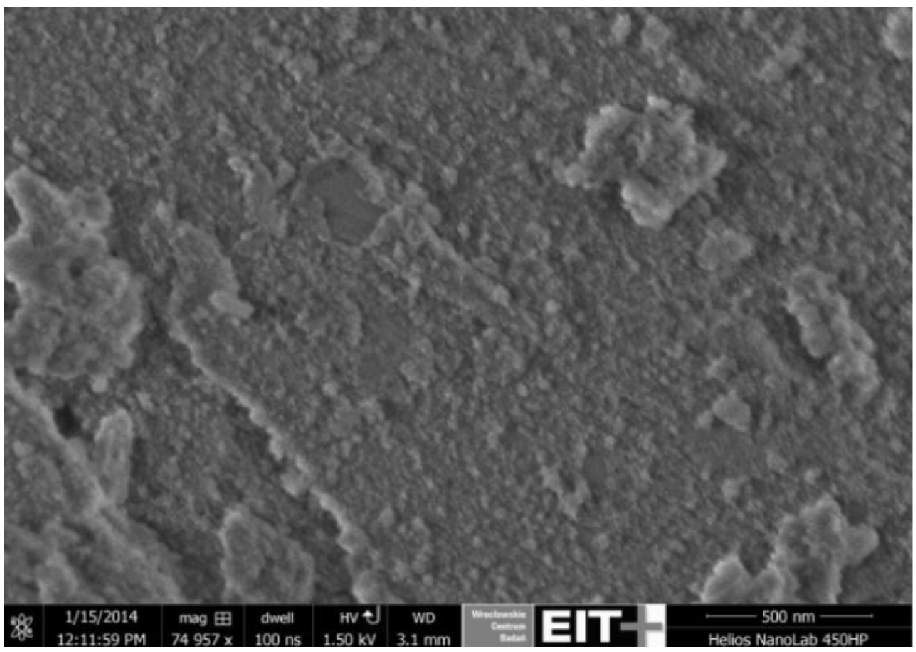

Figure 11. Surface of serpentinite ore befor leaching.

\section{Conclusions}

This paper discusses how dissolution of serpentinite in acid media can be modelled. Based on the experimental data, the following conclusions can be drawn.

1. The kinetics of serpentinite dissolution in $\mathrm{H}_{2} \mathrm{SO}_{4}$ solutions can be described by equations based on changes in the surface area.

2. There is a correlation between the extent of calcium and magnesium recovery and the increase in the particle surface area.

3. The dissolution process should be divided into two separated stages.

4. The shrinking core model is able to describe the second stage of the serpentinite rock dissolution process. 


\section{Acknowledgements}

The work was financed by a statutory activity subsidy from the Polish Ministry of Science and Higher Education for the Faculty of Chemistry of Wroclaw University of Technology.

\section{References}

1. A.Orlando, D.Borrini, L.Marini, Appl. Geochem., 26, 1569 (2011)

2. T.A.Haung, A.I.Munz, R.A.Kleiv, Energy Procedia, 4, 5029 (2011)

3. $\quad$ R.G.McDonald, B.I.Whittington, Hydrometallurgy, 91, 35 (2008)

4. S.Teir, H.Revitzer, S.Eloneva, C-J.Fogelholm, R.Zevenhoven, Int. J. Miner. Process., 83, 36 (2007)

5. M.M.Maroto-Valer, D.J.Fauth, M.E.Kuchta, Y.Zhang, J.M.Andresen, Fuel Process. Technol.., 86, $1627(2005)$

6. J.Baldyga, M.Henczka, K.Sokolnicka, Chem. Eng. Res. Des., 89, 1841 (2011)

7. S.C.M.Krevor, S.K.Lackner, Int. J. Greenh. Gas Con., 5, 1073 (2011)

8. M.Yoshimoto T.Koyama, Chem. Eng. Technol., 36(8), 1430 (2013)

9. I.S.Romao, LM.Gando-Ferreira, M.Manuela, V.G. da Silva, R.Zevenhoven, Miner. Eng., 94, 104 (2016)

10. A.Park, A.He. L-S.Fan, Chem. Eng. Sci., 59, 5241 (2004)

11. S.Teir, R.Kuusik, Int. J. Miner. Process., 85(1-3), 1 (2007)

12. X.Wang, M.M.Maroto-Valer, Fuel, 90, 1229 (2011)

13. A.M.Didyk, Z.Sadowski, Physicochem. Probl. Miner. Process., 48(2), 607 (2012)

14. V.Safari, G.Arzpeyma, F.Rashchi, N.Mostoufi, Int. J. Miner. Process., 93, 79 (2009)

15. H.Rutto, C.Enweremadu, Korean J. Chem. Eng., 29 (1), 1 (2012)

16. P.K.Gbor, C.QJia, Chem. Eng. Sci., 59, 1979 (2004)

17. H.M.Lizama, M.J.Fairweather, Z.Dai, T.D.Allegretto, Hydrometallurgy, 69, 109 (2003)

18. A.Szubert, R.Lupinski, Z.Sadowski, Physicochem. Probl. Miner. Process., 40, 211 (2006)

19. C.Fischer, R.Gaupp, Geochim. Cosmochim. Acta, 69(5), 1213 (2005)

20. B.Kieffe, F.C.Jove, H.E.Oelkers, J. Schott, Geochim. Cosmochim. Acta, 63(21), 3525 (1999)

21. H.M.Lizama, Miner. Eng., 18, 23 (2004) 